\title{
Structural Similarity on Multiple Length Scales and Its Relation to Devitrification Mechanism: A Solid-State NMR Study of Alkali Diborate Glasses and Crystals
}

\author{
Banghao Chen, ${ }^{\dagger}$ Ulrike Werner-Zwanziger, ${ }^{\dagger}$ Marcio L.F. Nascimento, ${ }^{\dagger}$ Luciana Ghussn,, \\ Edgar D. Zanotto, ${ }^{*}$ and Josef W. Zwanziger*, ${ }^{\star \dagger}$ \\ Department of Chemistry and Institute for Research in Materials, Dalhousie University, Halifax, Nova Scotia, \\ Canada, and Departamento de Engenharia de Materiais, Universidade Federal de São Carlos, \\ 13565-905 São Carlos, SP, Brazil
}

Received: July 29, 2009; Revised Manuscript Received: October 22, 2009

\begin{abstract}
The nature of the devitrification process is a fundamental problem in glass science and governs the ultimate stability of glass. It is hypothesized that the devitrification mechanism of a given glass composition is strongly correlated with the extent of structural similarity at the intermediate-range level between the glass and crystal phase to which it transforms. However, relatively little information is available to test this hypothesis because of the lack of long-range periodicity in glass and the absence of effective analysis methods. In this work $\mathrm{Li}_{2} \mathrm{O}-2 \mathrm{~B}_{2} \mathrm{O}_{3}(\mathrm{~L} 2 \mathrm{~B})$ and $\mathrm{Na}_{2} \mathrm{O}-2 \mathrm{~B}_{2} \mathrm{O}_{3}(\mathrm{~N} 2 \mathrm{~B})$ glasses, which respectively exhibit homogeneous (internal) and heterogeneous (surface) devitrification mechanisms, and corresponding crystals were prepared and comprehensively studied by using multiple solid state NMR techniques. Of those, ${ }^{11} \mathrm{~B}$ MAS and MQMAS experiments were applied to reveal short-range order information; ${ }^{7} \mathrm{Li}$ and ${ }^{23} \mathrm{Na}$ spin-echo decay and ${ }^{11} \mathrm{~B}\left\{{ }^{6} \mathrm{Li}\right\}$ and ${ }^{11} \mathrm{~B}\left\{{ }^{23} \mathrm{Na}\right\}$ rotational echo double resonance (REDOR) experiments were used to determine homonuclear and heteronuclear interactions that can reflect the intermediate-range order. It was found that the local bonding environments of the L2B crystal and glass are quite similar, whereas there are significant differences in the N2B system. Moreover, the experimental results indicated that the second moment $\left(\mathrm{M}_{2}\right)$ values of both homo- and heterodipolar interactions measured for the L2B glass are very close to those of its isochemical crystal, in contrast, the $\mathrm{M}_{2}$ values for N2B glass differ significantly from those of its crystal phase. These observations indicate the existence of a strong correlation between structural similarity at both the short and intermediate length scale, and nucleation mechanism.
\end{abstract}

\section{Introduction}

Glass-ceramics are important materials with a wide range of applications, and interest in the study and development of various glass-ceramics is strong. ${ }^{1}$ They can be produced through controlled glass devitrification, a process by which thermodynamically metastable glass undergoes structural rearrangement to form stable crystalline compounds. There are two general devitrification mechanisms in glass: (1) homogeneous nucleation starting from the volume within the glass and (2) heterogeneous nucleation originating from surfaces and impurities. ${ }^{1 \mathrm{a}, 2}$ The relationship between glass structure, devitrification rate, and the structures of the resulting crystalline phase(s) are important for both applications and a fundamental understanding of the glassy state. It is hypothesized that structural similarities between the glass and the crystalline compound formed through devitrification either determine the mechanism followed, or at least correlate strongly with it. ${ }^{3}$ However, relatively little information is available to test this hypothesis because of the lack of longrange periodicity in glass and the absence of analysis methods that can be used to determine the intermediate-range order (3-10 ̊). ${ }^{4}$ Numerous glass studies have focused on studying short-range order $(1.5-3 \AA)$ in glass, i.e., the first-neighbor coordination environments ${ }^{5}$ and tetrahedral connectivity. ${ }^{6}$ The problem is that typically the features of the local environment

* To whom correspondence should be addressed. Tel: (902) 494-1960. E-mail: jzwanzig@dal.ca.

$\dagger$ Dalhousie University.

* Universidade Federal de São Carlos. of glass are essentially the same as those of analogous crystalline phases, regardless of the nucleation mechanism. ${ }^{5 \mathrm{c}, 7}$ This is especially true for silicates but may be less so for other glass formers with more complex bonding motifs.

Recent developments in solid-state NMR make it a viable approach to probe both the short- and intermediate-range order of glasses. ${ }^{4,8}$ High resolution experiments (like MAS and MQMAS) in strong magnetic fields are usually applied to give short-range order information about various glass systems. ${ }^{9}$ These results are necessary but not always sufficient to reveal the relationship between the structural similarity and the nucleation mechanism. With regard to the intermediate-order in glass, such as the spatial distribution of the network-modifier ions, suitable solid state NMR experiments that probe the magnetic dipole-dipole couplings are particularly valuable. That is because dipolar interactions act through space between any pair of nuclei possessing nonzero spin. In principle they are calculable from the internuclear distances, and therefore, the measurement of these interactions is of particular relevance in the structural analysis of glasses. ${ }^{10}$ Very recently, the hypothesis that the structural similarities between glass and its corresponding crystalline phase influence the devitrification mechanism was confirmed in lithium and sodium disilicates by using NMR spin-echo techniques, ${ }^{11}$ but a single system is not a very rigorous check. Moreover, because the local bonding around silicon in silicates tends to be particularly well-defined as compared to other main-group glass formers, it is important to 
TABLE 1: Preparation Conditions of L2B and N2B Glass and Corresponding Crystalline Samples Studied in This Work $^{a}$

\begin{tabular}{|c|c|c|c|c|c|c|}
\hline \multirow[b]{2}{*}{ starting materials } & \multirow[b]{2}{*}{ glass } & \multicolumn{2}{|c|}{ melting } & \multirow[b]{2}{*}{ crystal } & \multicolumn{2}{|c|}{ crystallization } \\
\hline & & $T\left({ }^{\circ} \mathrm{C}\right)$ & $t(\mathrm{~h})$ & & $T\left({ }^{\circ} \mathrm{C}\right)$ & $t(\mathrm{~h})$ \\
\hline $\mathrm{Li}_{2} \mathrm{~B}_{4} \mathrm{O}_{7} \cdot 10 \mathrm{H}_{2} \mathrm{O}$ & $\mathrm{L} 2 \mathrm{Bg}$ & 1000 & 2 & $\mathrm{~L} 2 \mathrm{Bc}^{a}$ & 510 & 20 \\
\hline $\mathrm{Na}_{2} \mathrm{~B}_{4} \mathrm{O}_{7} \cdot 10 \mathrm{H}_{2} \mathrm{O}$ & $\mathrm{N} 2 \mathrm{Bg}^{a}$ & 900 & 3 & $\mathrm{~N} 2 \mathrm{Bc}^{a}$ & 520 & 3 \\
\hline
\end{tabular}

test the hypothesis in nonsilicate oxides (and eventually of course in nonoxides, metals, etc.).

Borate glasses are important glass systems with many applications. ${ }^{12}$ Lithium diborate $\left(\mathrm{Li}_{2} \mathrm{O} \cdot 2 \mathrm{~B}_{2} \mathrm{O}_{3}, \mathbf{L} 2 \mathrm{~B}\right)$ and sodium diborate $\left(\mathrm{Na}_{2} \mathrm{O} \cdot 2 \mathrm{~B}_{2} \mathrm{O}_{3}, \mathbf{N} 2 \mathrm{~B}\right)$ respectively exhibit homogeneous and heterogeneous devitrification mechanisms. ${ }^{13}$ It is very interesting to compare the structural similarity between these diborate glasses and their crystalline phases with known structures. ${ }^{14}$ However, to the best of our knowledge no such comparison study has been reported yet, especially by NMR. There are several complicating factors in using NMR to study these systems. First, the dipolar interactions in these systems are quite complex compared to silicates because the nuclei present $\left({ }^{6} \mathrm{Li},{ }^{7} \mathrm{Li},{ }^{23} \mathrm{Na},{ }^{11} \mathrm{~B}\right.$, and $\left.{ }^{10} \mathrm{~B}\right)$ in $\mathrm{L} 2 \mathrm{~B}$ and $\mathrm{N} 2 \mathrm{~B}$ glasses are both relatively abundant and quadrupolar. The quadrupolar interactions lead to much more complex magnetization trajectories than in spin-1/2 systems, and so standard dipole-dephasing experiments become difficult to apply quantitatively. ${ }^{15,16} \mathrm{In}$ addition, the bonding environments of boron are more diverse than those of silicon, leading to a wider variety of sites and couplings.

As the detailed structures of L2B and N2B glass are unknown, it is impossible to calculate the spin dipolar interactions directly. However, as the crystalline $\mathrm{Li}_{2} \mathrm{~B}_{4} \mathrm{O}_{7}$ and $\mathrm{Na}_{2} \mathrm{~B}_{4} \mathrm{O}_{7}$ phases have the same chemical compositions as the $\mathrm{L} 2 \mathrm{~B}$ and $\mathrm{N} 2 \mathrm{~B}$ glasses, they can be used as ideal model compounds to calculate the contributions of spin dipolar interactions based on the crystal structure derived from X-ray diffraction. ${ }^{17}$ The experimental conditions and parameters used for the model compounds can be optimized by comparing the experimental results with the calculated values and then applied to measure investigated samples. In this work, L2B and N2B glasses and corresponding crystal phases were prepared, and their intermediate range orderings were studied by multiple solid-state NMR techniques. The derived structural models of the glasses as compared with the crystals show a significant correlation between structural similarity and nucleation mechanism in alkali borate glasses.

\section{Experimental Section}

Sample Preparation. The L2B and N2B samples were prepared by the standard melt-quenching approach. A typical procedure was the following: mixtures of starting materials (alkali diborate decahydrates of analytical purity) in appropriate proportions were melted in platinum crucibles in a furnace at $900-1000{ }^{\circ} \mathrm{C}$ for $2-3 \mathrm{~h}$ before quenching in air. Splat cooling method with iron molds was applied for N2B glass, and L2B glass was only obtained by quenching the platinum crucible with super cooled liquid inside. Part of the glass samples were crystallized by holding them at specific temperatures for sufficient times (Table 1). In order to reduce the $T_{1}$ relaxation time of the observed nuclei, trace amounts of paramagnetic $\mathrm{Mn}^{2+}$ were added, which is regarded to be no affection to the structure of the glass. ${ }^{18}$
Phase Identification and Thermal Analysis. Powder XRD measurements were conducted to determine the phase purity of the crystal samples. The patterns were recorded on a Bruker D8 Advance powder X-ray diffractometer in Bragg-Brentano configuration using $\mathrm{Cu} \mathrm{K \alpha}$ radiation $(\lambda=1.5406 \AA)$ and graphite monochromator with $0.02 \%$ step width. The samples were rotated during data collection. Differential scanning calorimetry (DSC) was carried out in air on a Netzsch 404 apparatus by using fine powder samples with a heating rate of $10 \mathrm{k} / \mathrm{min}$.

NMR Studies. For known crystal structures, the summation of the distribution of the dipolar interactions between a center nucleus and its environment (including like and unlike nuclei), and therefore the van Vleck second moment, ${ }^{10,19}$ can be calculated based on the following equations:

$$
\begin{gathered}
M_{2}=E_{\mathrm{L}}\left(\mu_{0} / 4 \pi\right)^{2} \gamma^{4} \hbar^{2} \sum_{j} \mathrm{r}_{i j}{ }^{-6} \\
M_{2}(\mathrm{I}-\mathrm{S})=4 / 15\left(\mu_{0} / 4 \pi\right)^{2} \gamma_{\mathrm{S}}^{2} \gamma_{\mathrm{I}}^{2} S(S+1) \hbar^{2} \sum_{s} r_{\mathrm{IS}}{ }^{-6}
\end{gathered}
$$

In eq $1 \mathrm{a}, M_{2}$ is the homonuclear second moment for quadrupolar nuclei in one of the central transition states. ${ }^{20} E_{\mathrm{L}}$ is a prefactor, where for spin $3 / 2$ nuclei (like ${ }^{23} \mathrm{Na}$ and ${ }^{7} \mathrm{Li}$ in this study) $E_{\mathrm{L}}$ is $0.9562 .{ }^{20 \mathrm{a}} \mathrm{In}$ eq $1 \mathrm{~b}, M_{2}(\mathrm{I}-\mathrm{S})$ is the heteronuclear second moment for nucleus I dipole-coupled to surrounding heteronuclei S. $S$ refers to the spin quantum number of the unobserved nucleus. $\gamma$ is the gyromagnetic ratio of nuclei in both equations. Both $M_{2}$ and $M_{2}(\mathrm{I}-\mathrm{S})$ are related to the distances between interacting nuclei and proposed to be quantitative measures of intermediate-range order.

Spin-echo decay experiment (pulse sequences are shown in Supporting Information, Figure S1) can be used to measure the homonuclear dipolar interactions effectively. ${ }^{20,21}$ For a spin system characterized by multiple interactions the decay of the echo amplitude as a function of the pulse spacing $\tau$ is Gaussian and allows the measurement of an average homonuclear second moment $M_{2}$.

$$
I_{(2 \tau)} / I_{0}=\exp \left[-\left(M_{2} / 2\right)(2 \tau)^{2}\right]
$$

$I_{0}$ is the signal intensity extrapolated at $\tau=0$. Based on this equation, $M_{2}$ can be extracted by fitting the initial decay ( $2 \tau \leq$ $200 \mu \mathrm{s}$ ) of the curve because the initial intensity loss is dominated by the spin-spin relaxation due to the homonuclear dipolar coupling. To quantitatively measure the $M_{2}$ of quadrupolar nuclei without the effects of electric quadrupolar interactions (to first order), an appropriate selective excitation of central transition is very important. For quadrupolar nuclei like ${ }^{23} \mathrm{Na}$ with relatively large quadrupolar coupling constants $\left(C_{\mathrm{q}}\right)$, the selective excitation can be accomplished relatively easily by choosing appropriate rf field strengths. ${ }^{4}$ But for quadrupolar nuclei with relatively small $C_{\mathrm{q}}$ like ${ }^{7} \mathrm{Li}$ involved in present study, the selective excitation becomes difficult and the very long pulse lengths and low rf powers are necessary. ${ }^{11}$ This may be the main reason why very few results have been reported for ${ }^{7} \mathrm{Li}$. Exploration of the experimental conditions and interpretation of the ${ }^{7} \mathrm{Li}-{ }^{7} \mathrm{Li}$ average homodipolar second moment in lithium glass is also one of the goals of our present experiments. 


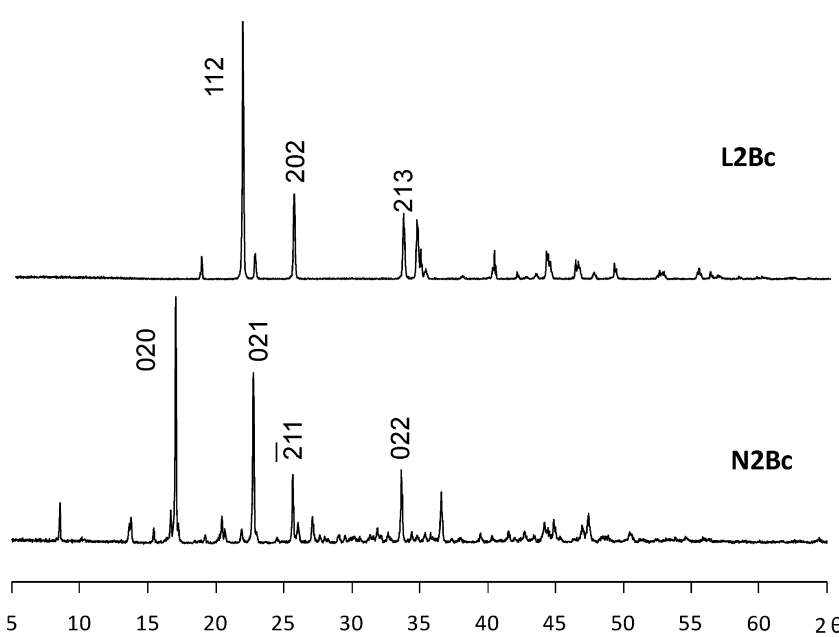

Figure 1. Powder XRD patterns of crystallized lithium diborate and sodium diborate.

For the heteronuclear dipolar interactions, Rotational Echo Double Resonance (REDOR) experiment has been proved to be quite useful. ${ }^{22,23}$ The initial part of REDOR dephasing curve $\left(S_{0}-S\right) / S_{0}(<0.2)$ can be fitted by a modified eq $2 \mathrm{~b}$ to a parabolic approximation in which $M_{2}(\mathrm{I}-\mathrm{S})$ is the only unknown. ${ }^{24}$

$$
\left(S_{0}-S\right) / S_{0}=\left(f /\left(I(I+1) \pi^{2}\right)\right)\left(\mathrm{NT}_{\mathrm{r}}\right)^{2} M_{2}(I-S)
$$

Here, $f(0<f<1)$ is a calibration factor accounting for systematic effects introduced by the I-I homodipolar coupling, the quadrupolar splitting of the I nuclei, and experimental imperfections. The approach used in this study is to calibrate the experimental parameter by conducting REDOR experiments on crystalline model compounds $\left(\mathrm{Li}_{2} \mathrm{~B}_{4} \mathrm{O}_{7}\right.$ and $\left.\mathrm{Na}_{2} \mathrm{~B}_{4} \mathrm{O}_{7}\right)$ with known structures, identical compositions, and similar spin dynamics as the glasses. The calibration factor $\mathrm{f}$ can be determined based on the $M_{2}(\mathrm{I}-\mathrm{S})$ values of crystals calculated from the known structures. $I$ is the spin quantum number of the observed nucleus (here, $I=3 / 2$ for ${ }^{11} \mathrm{~B}$ ). $\mathrm{NT}_{\mathrm{r}}$ is a multiple of the rotor period $\left(T_{\mathrm{r}}\right)$ that can be used to modulate the amount of dipolar dephasing by changing the number $N$.

All NMR experiments were collected on two Bruker Avance NMR spectrometers operating at magnetic fields of 9.4 and 16.4 T. The ${ }^{11} \mathrm{~B}$ MAS and Multiple Quantum (3Q) MAS NMR spectra were collected at $224.67 \mathrm{MHz}$ with a $2.5 \mathrm{~mm}$ Bruker MAS probe operating at $16.4 \mathrm{~T}$. For ${ }^{11} \mathrm{~B}$ MAS experiments,

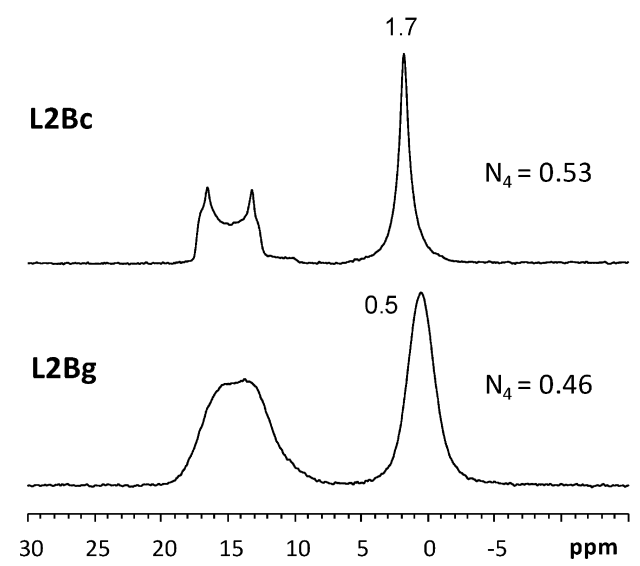

Figure 2. ${ }^{11} \mathrm{~B}$ MAS NMR spectra of $\mathrm{L} 2 \mathrm{Bg}, \mathrm{L} 2 \mathrm{Bc}, \mathrm{N} 2 \mathrm{Bg}$, and N2Bc. single pulse acquisition was applied with spinning rate of 20 $\mathrm{kHz}$ and a short RF pulse ( $\mathrm{rf}$ field strength of $78.4 \mathrm{kHz}$ ) of 0.4 $\mu$ s (less than one-sixth of the liquid $90^{\circ}$ pulse duration to obtain quantitative relative peak areas for sites with different $C_{\mathrm{q}}{ }^{25}$ ) was used with a recycle delay of 10-15 s. Data were background corrected by subtraction of the empty rotor signal. All the spectra are referenced to solid $\mathrm{NaBH}_{4}$ at $-42.16 \mathrm{ppm} .{ }^{11} \mathrm{~B} 3 \mathrm{QMAS}$ spectra were obtained using a split $t_{1}$ three-pulse sequence with full echo acquisition. ${ }^{26}$ The triple quantum excitation pulse of 4.2 and $1 \mu$ s conversion pulse, both with $100 \mathrm{kHz}$ fields, were followed by a $180^{\circ}$ selective pulse of $32 \mu$ s at approximately $15 \mathrm{kHz}$ field strength. The delay between the second and third pulses was rotor synchronized and set to 64 rotor periods to allow for full echo buildup. A recycle delay of $20 \mathrm{~s}$ was used, validated by relaxation time measurements. The spinning speed is $25 \mathrm{kHz}$ and the spectral width in the MAS dimension was set to $50 \mathrm{kHz}$, and 96 scans were accumulated for each of 128 $t_{1}$ experiments with 8 dummy scans. The slices through the MQMAS spectrum for different Boron sites with identical isotropic (f1) frequencies were simulated by DMfit program. ${ }^{27}$

For the ${ }^{23} \mathrm{Na}$ and ${ }^{7} \mathrm{Li}$ spin-echo experiments a Hahn echo sequence was used under static conditions. To minimize the effects of magnetic field inhomogeneity only the center third of the rotor was filled with sample. Experiments were performed at room temperature and in addition for the $\mathrm{N} 2 \mathrm{~B}$ glass and crystal samples at 183 and $200 \mathrm{~K}$, respectively. The pulse powers ofb $^{23} \mathrm{Na}$ experiments were $8.2-11.4 \mathrm{kHz}$ to achieve selective excitation of the central transition. At this power level $\pi / 2$ pulses were optimized to be between 11 and $15.5 \mu$ s and $\pi$ pulses 22 to $31 \mu$ s. Recycle delays used were between 10 and $200 \mathrm{~s}$. For the ${ }^{7} \mathrm{Li}$ experiments pulse powers of $4.0-4.4 \mathrm{kHz}$ were used to achieve selective excitation of the central transition, the $\pi / 2$ and $\pi$ pulse lengths at these powers were 28.0-30.7 and $56.0-61.4 \mu \mathrm{s}$, respectively. Recycle delays were between 70 and $600 \mathrm{~s}$. These extremely long relaxation times for the L2B glass sample in combination with the very fast ${ }^{7} \mathrm{Li}$ echo decay, which rendered the initial part of the Spin echo decay unobservable (spectrometer dead time problem), caused us to collect relatively few, nevertheless sufficient amounts of data points for an unambiguous fitting to give a reliable $M_{2 \mathrm{E}}$ value.

For the REDOR experiments, the pulse lengths of the observed nucleus I were optimized by maximizing the signal from the experiments without dephasing the unobserved nucleus, S. The $\pi$ pulse on the unobserved nucleus was optimized by minimizing the signal of the experiment with $\mathrm{S}$ dephasing. As to the ${ }^{11} \mathrm{~B}\left\{{ }^{23} \mathrm{Na}\right\}$ experiments, ${ }^{11} \mathrm{~B} \pi / 2$ pulses and $\pi$ pulses were typically 4.6 and $9.2 \mu \mathrm{s}$. ${ }^{23} \mathrm{Na} \pi$ pulse length was $18 \mu$ s at a

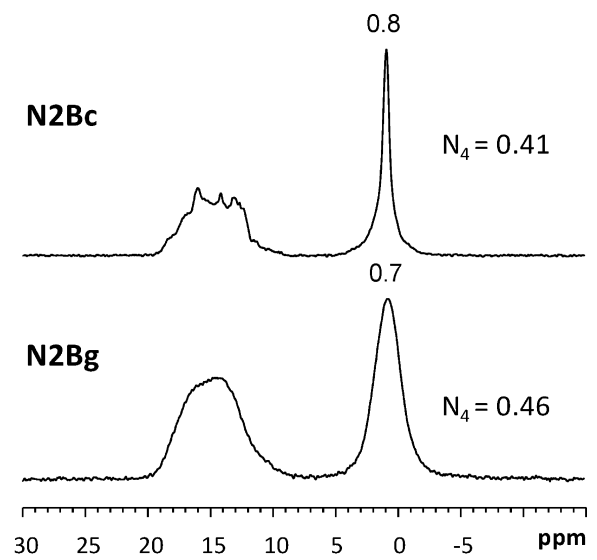



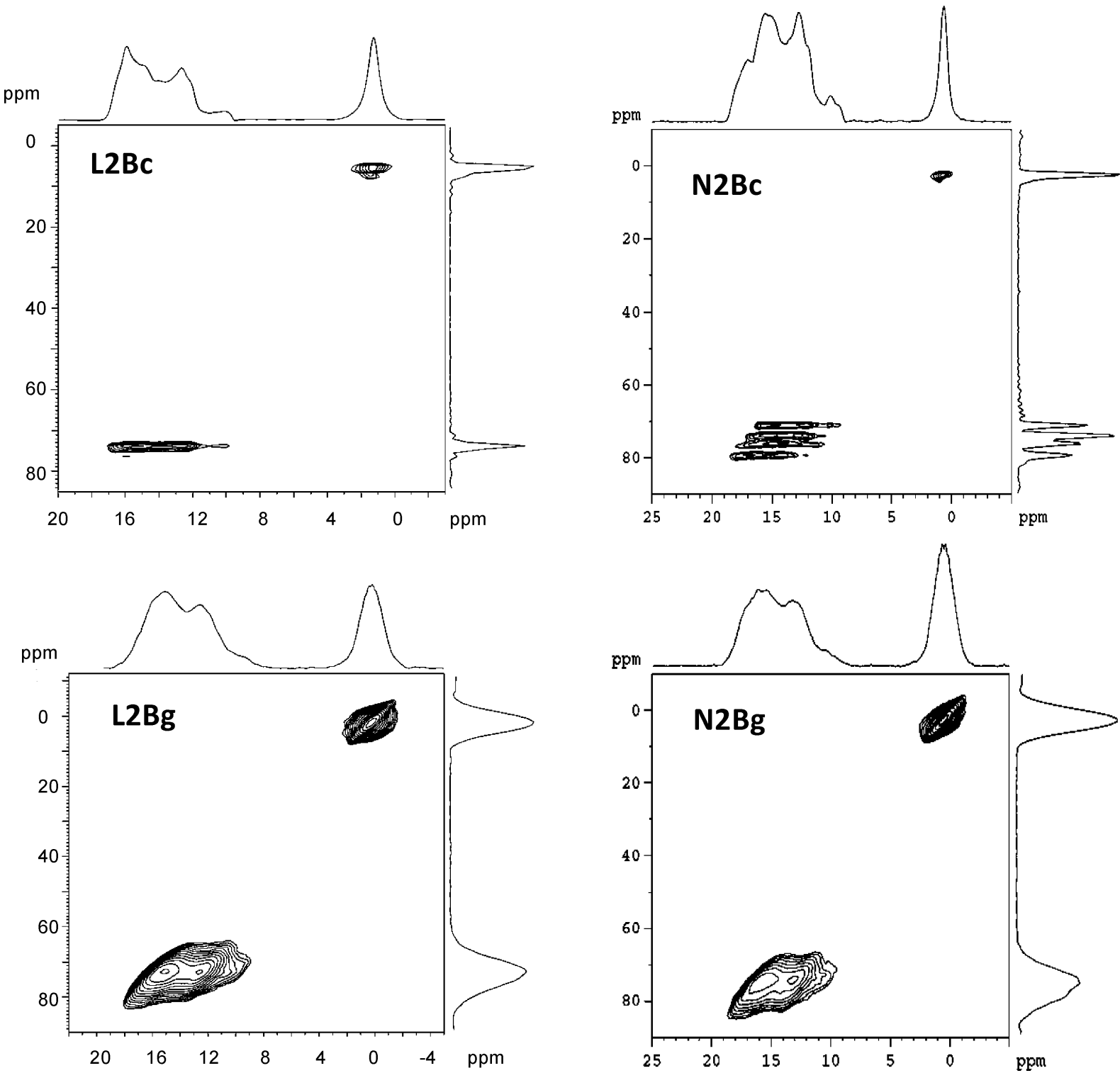

Figure 3. ${ }^{11} \mathrm{~B}$ MQMAS spectra of $\mathrm{L} 2 \mathrm{Bg}, \mathrm{L} 2 \mathrm{Bc}, \mathrm{N} 2 \mathrm{Bg}$, and $\mathrm{N} 2 \mathrm{Bc}$.

power of $14 \mathrm{kHz}$. For the ${ }^{11} \mathrm{~B}\left\{{ }^{6} \mathrm{Li}\right\}$ experiments, ${ }^{11} \mathrm{~B} \pi / 2$ and $\pi$ pulses were 4.5 and $9.3 \mu$ s, respectively. ${ }^{6} \mathrm{Li} \pi$ pulse was 12.5 $\mu$ s at a power of $20 \mathrm{kHz}$. In most experiments 8 or 16 scans were used. The spinning speeds were varied from 10 to $12 \mathrm{kHz}$ with typical recycle delays varied from 40 to $60 \mathrm{~s}$.

\section{Results and Discussions}

The XRD patterns of crystallized $\mathrm{L} 2 \mathrm{Bc}$ and $\mathrm{N} 2 \mathrm{Bc}$ are shown in Figure 1. They are in good agreement with those of reported $\mathrm{Li}_{2} \mathrm{~B}_{4} \mathrm{O}_{7}$ and $\mathrm{Na}_{2} \mathrm{~B}_{4} \mathrm{O}_{7}$ crystals (JCPDS card 79-0963 and 291179). High intensity of the main characteristic reflections and the absence of any amorphous halo in the XRD patterns indicate that the products are highly crystalline. Therefore, L2Bc and N2Bc samples can be used as model compounds in this study and their crystal structures ${ }^{14}$ derived from X-ray diffraction can be used to calculate the contributions of spin dipolar interactions within the crystal samples.

The DSC results of the investigated samples are listed in the Supporting Information, Table S1. For several stoichiometric oxide glass forming systems, a simple rule of thumb has been demonstrated to be able to predict the nucleation mechanism by comparing the glass transition temperature $\left(T_{\mathrm{g}}\right)$ and the melting/liquidus temperature $\left(T_{\mathrm{m}}\right){ }^{28}$ Compositions with small values of reduced glass transition temperatures $\left(T_{\mathrm{gr}}=T_{\mathrm{g}} / T_{\mathrm{m}}\right)$, $T_{\mathrm{gr}}<0.6$, show homogeneous nucleation on laboratory time scales. On the other hand, for the majority of glasses with the typical high values of $T_{\mathrm{gr}}(>0.6)$, only heterogeneous nucleation is observed on laboratory time scales. For the investigated L2B and $\mathrm{N} 2 \mathrm{~B}$ samples, the measured $T_{\mathrm{gr}}$ values are 0.6 and 0.7 , respectively. According to above rule, the nucleation mechanism of system N2B $\left(T_{\mathrm{gr}}>0.6\right)$ is heterogeneous, while the nucleation mechanism of system of L2B $\left(T_{\mathrm{gr}}=0.6\right)$ is on the edge of homogeneous. However, the nucleation mechanism of L2B was already unambiguously confirmed to be homogeneous by previous differential thermal analysis study based on classic nucleation theory. ${ }^{13 a}$

To characterize the $\mathrm{B}-\mathrm{O}$ network (main structure in alkali diborate glasses), ${ }^{11} \mathrm{~B}$ MAS and MQMAS NMR experiments were employed. Figure 2 shows the single pulse ${ }^{11} \mathrm{~B}$ MAS spectra of the investigated samples. All the spectra reveal two distinct spectral components: a sharp line at around $1 \mathrm{ppm}$ assigned to tetrahedral $\left[\mathrm{BO}_{4 / 2}\right]^{-}$(i.e., B4) sites, and the downfield broad resonances for glass samples and quadrupolar powder patterns for crystals centered around $15 \mathrm{ppm}$ assigned to $\left[\mathrm{BO}_{3 / 2}\right]$ 
(i.e., B3 sites). The broadening of the B4 resonances for glass samples comes from the distribution of ${ }^{11} \mathrm{~B}$ chemical shifts that reflect the structural disorder in the glass, such as bond angles, bond-length variations, etc. The $\mathbf{N}_{4}(=\mathrm{B} 4 /(\mathrm{B} 4+\mathrm{B} 3))$ values of $\mathrm{L} 2 \mathrm{Bc}$ and $\mathrm{N} 2 \mathrm{Bc}$ are 0.53 and 0.41 , which are consistent with the theoretical values of 0.50 and 0.38 based on the crystal structures obtained by X-ray analysis. ${ }^{14}$

Careful inspection shows that (1) the chemical shift of the B4 site shifted to downfield by $1.2 \mathrm{ppm}$ during the L2B crystallization, showing the small structural changes of this high symmetry site, while that of $\mathrm{N} 2 \mathrm{~B}$ system shifts only marginally upon devitrification and (2) the $\mathrm{N}_{4}$ values of glasses for both systems are slightly different from those of corresponding crystalline phases, which may be due to the rearrangement of borate groups in the nucleation process. ${ }^{13 \mathrm{~d}}$ The B3-signals of both glasses are broadened and ill-defined, while those of the two crystals exhibit quadrupole patterns. The typical quadrupole patterns in the L2B crystal spectrum is due to the single B3 site predicted from the crystal structure and the overlapping patterns of the N2B crystal indicate the existence of multiple B3 sites. In order to show unambiguously the number of distinct boron sites present in each system and their similarities between the glasses and crystals, MQMAS experiments were employed. The ${ }^{11} \mathrm{~B}$ MQMAS spectra are shown in Figure 3 and Supporting Information, Figure S2. The vertical scales of the isotropic shifts are derived from the triple quantum evolution times. This dimension is used only to separate the different sites. The NMR parameters for the different sites are obtained by fits $^{27}$ of
TABLE 2: Isotropic Chemical Shift $(\delta)$, Nuclear Electronic Quadrupolar Coupling Constant $\left(C_{\mathrm{q}}\right)$, and Electronic Field Gradient Asymmetry Parameter $(\eta)$ of B3 and B4 Sites of L2B and N2B Samples Obtained by Simulation of NMR Spectra $^{a}$

\begin{tabular}{clrcl}
\hline samples & B sites & \multicolumn{1}{c}{$\delta(\mathrm{ppm})$} & $\eta$ & \multicolumn{1}{c}{$C_{\mathrm{q}}(\mathrm{MHz})$} \\
\hline L2Bg & B4 & $0.6 \pm 0.2$ & & $\leq 0.9$ \\
& B3 & $17.0 \pm 0.2$ & $0.23 \pm 0.03$ & $2.54 \pm 0.02$ \\
$\mathbf{L 2 B c}$ & B4 & $1.5 \pm 0.3$ & & $\leq 0.7$ \\
& B3 & $17.5 \pm 0.3$ & $0.17 \pm 0.02$ & $2.59 \pm 0.02$ \\
$\mathbf{N 2 B g}$ & B4 & $0.8 \pm 0.3$ & & $\leq 0.6$ \\
& B3* & $19.1 \pm 0.2$ & $0.10 \pm 0.02$ & $2.62 \pm 0.04$ \\
& B3* & $18.3 \pm 0.2$ & $0.20 \pm 0.03$ & $2.59 \pm 0.04$ \\
& B3* & $17.5 \pm 0.3$ & $0.25 \pm 0.02$ & $2.56 \pm 0.04$ \\
& B3* & $16.5 \pm 0.2$ & $0.30 \pm 0.02$ & $2.50 \pm 0.04$ \\
N2Bc & B4 & $0.6 \pm 0.3$ & & $\leq 0.3$ \\
& B3(1) & $19.0 \pm 0.2$ & $0.20 \pm 0.02$ & $2.66 \pm 0.04$ \\
& B3(2) & $17.9 \pm 0.3$ & $0.65 \pm 0.02$ & $2.48 \pm 0.04$ \\
& B3(3,4) & $17.5 \pm 0.3$ & $0.20 \pm 0.03$ & $2.63 \pm 0.05$ \\
& B3(5) & $17.0 \pm 0.2$ & $0.00 \pm 0.02$ & $2.59 \pm 0.04$
\end{tabular}

${ }^{a}$ Asterisks mark distributions of B3 sites. The B4 sites all have small quadrupole couplings and hence indeterminate asymmetry parameters.

individual slices parallel to the magic angle spinning axis. The results are listed in Table 2.

For L2Bc, the isotopic dimension of the MQMAS spectrum clearly shows that there is only one resolved B3 and one B4 site $(50 \%$ each based on MAS), consistent with the crystal
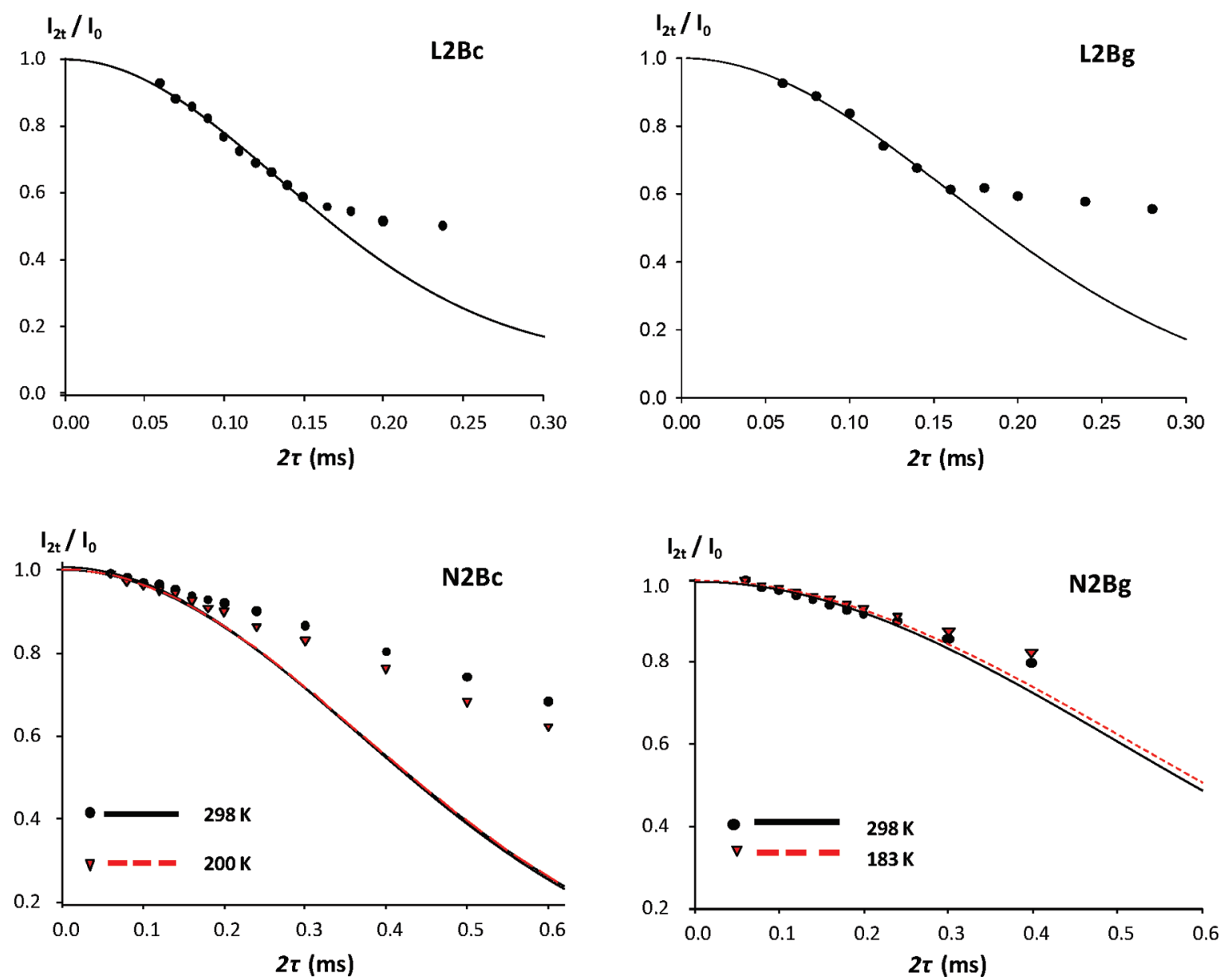

Figure 4. ${ }^{7} \mathrm{Li}$ and ${ }^{23} \mathrm{Na}$ spin-echo decay curves of L2B (up) and N2B (down) samples measured at room temperature and low temperature. $M_{2 \mathrm{E}}$ is determined by fitting the data points $(2 \tau \leq 200 \mu \mathrm{s})$ to eq $2 \mathrm{a}$. The solid lines are the curves fitted for the room temperature experiments and the dashed lines for those carried at low temperatures. 
TABLE 3: Experimental and Calculated Second Moments for Crystalline Model Compounds

\begin{tabular}{lccl}
\hline samples & spin-spin & $M_{2 \mathrm{E}}\left(10^{6} \mathrm{rad}^{2} / \mathrm{s}^{2}\right)$ & $M_{2 \mathrm{C}}\left(10^{6} \mathrm{rad}^{2} / \mathrm{s}^{2}\right)$ \\
\hline $\mathrm{Li}_{2} \mathrm{CO}_{3}$ & & $148 \pm 15$ & 152 \\
$\mathrm{LiNbO}_{3}$ & ${ }^{7} \mathrm{Li}-{ }^{7} \mathrm{Li}$ & $52 \pm 5$ & $35-64,{ }^{29} 79^{15 \mathrm{a}}$ \\
$\mathrm{LiF}$ & & $452 \pm 40$ & $422^{30}$ \\
$\mathrm{Na}_{2} \mathrm{SO}_{4}$ & & $11.0 \pm 1.0$ & $12.7^{20 \mathrm{~b}}$ \\
$\mathrm{Na}_{2} \mathrm{SO}_{3}$ & ${ }^{23} \mathrm{Na}-{ }^{23} \mathrm{Na}$ & $14.8 \pm 1.5$ & $16.0^{20 \mathrm{~b}}$ \\
$\mathrm{NaNO}_{2}$ & & $7.2 \pm 0.7$ & $7.6^{20 \mathrm{~b}}$
\end{tabular}

structure. ${ }^{14 a}$ The MQMAS spectrum of L2Bg also exhibits only one type of B3 and B4 sites with chemical shift distributions. The parameters of the B3 and B4 sites obtained by simulation for $\mathrm{L} 2 \mathrm{Bg}$ are very similar to those of $\mathrm{L} 2 \mathrm{Bc}$. There are five distinct B3 sites and one type of B4 site (no resolvable anisotropic pattern) for crystalline $\mathrm{N} 2 \mathrm{Bc}$, which is in agreement with the crystal structure obtained by X-ray analysis. ${ }^{14 \mathrm{~b}}$ However, the $\mathrm{B} 3$ region of the $\mathrm{N} 2 \mathrm{Bg}$ does not show resolved distinct sites. Fitting the individual slices reveals continuously varying quadrupolar and chemical shift parameters as given in Table 2. In contrast to the L2B system, where glass and crystal have similar quadrupole parameters, the B3(2) and B3(5) sites in $\mathrm{N} 2 \mathrm{Bc}$ (with their large and vanishing asymmetry parameters, $\eta$, respectively) have no analog in the glassy state (Table 2). The results indicate that for the L2B system, known to crystallize by a homogeneous nucleation mechanism, the glass and crystallized phases have very similar B3 and B4 local environments. For the N2B system, known to crystallize by a heterogeneous nucleation mechanism, the B4 sites of glass and crystal have similar local environment but the B3 sites exhibit different features. These results indicate that the difference of the nucleation mechanisms of $\mathrm{N} 2 \mathrm{~B}$ and L2B systems are correlated with their local structures. Similar differences in local structure between glass and crystal were not observed in the analogous silicates, presumably because the silicon bonding environments show much less variability than do the borates.

To determine the $\mathrm{Li}$ and $\mathrm{Na}$ local environments in the investigated samples, ${ }^{6} \mathrm{Li} \mathrm{MAS},{ }^{23} \mathrm{Na} \mathrm{MAS}$, and ${ }^{23} \mathrm{Na}$ MQMAS were also conducted. No significant differences were observed between the spectra of the glass and crystal samples (data not shown).

In order to understand fully the structure-nucleation relationship, we need to extend the structural characterization beyond the nearest neighbor sphere. Here, spin-echo decay and REDOR experiments were applied to determine the homonuclear and heteronuclear dipolar interactions between nuclei, which can be used to reveal the features of the intermediaterange order of the investigated samples. For the spin-echo experiments, we first explored the experimental pulse power dependence under current study conditions by measuring $\mathrm{M}_{2}$ of selected crystalline model compounds with known structures as a function of excitation bandwidth. As the ${ }^{23} \mathrm{Na}$ sites in these samples show relatively large quadrupole couplings $\left(C_{\mathrm{q}}\right)$, it is relatively easily to find a moderate pulse power that excites the ${ }^{23} \mathrm{Na}$ central transition with minimal coherence in the satellite transitions. For ${ }^{7} \mathrm{Li}$, however, the small $C_{\mathrm{q}}$ makes it difficult to find selective excitation conditions. In this case very long pulse lengths and low rf powers are necessary, however, too weak pulses would fail in the excitation and result in erroneous $M_{2}$ measurements. After careful pulse power selection, good agreement between the experimental $M_{2 \mathrm{E}}$ and the calculated $M_{2 \mathrm{C}}$ for model compounds was achieved (Table 3 ). The experimental conditions and parameters giving the best $M_{2}$ matches were then applied to measure the samples of interest. Sufficient recycle
TABLE 4: Experimental and Calculated Second Moments of L2B and N2B Samples

\begin{tabular}{|c|c|c|c|c|}
\hline samples & spin - spin & $\begin{array}{l}M_{2 \mathrm{E}}\left(10^{6} \mathrm{rad}^{2} / \mathrm{s}^{2}\right) \\
\text { room temperature }\end{array}$ & $\begin{array}{l}M_{2 \mathrm{E}}\left(10^{6} \mathrm{rad}^{2} / \mathrm{s}^{2}\right) \\
\text { low temperature }\end{array}$ & $\begin{array}{c}M_{2 \mathrm{C}} \\
\left(10^{6} \mathrm{rad}^{2} / \mathrm{s}^{2}\right)\end{array}$ \\
\hline L2Bc & ${ }^{7} \mathrm{Li}-{ }^{7} \mathrm{Li}$ & $42 \pm 4$ & & 43 \\
\hline L2Bg & & $39 \pm 4$ & & \\
\hline N2Bc & ${ }^{23} \mathrm{Na}-{ }^{-3} \mathrm{Na}$ & $7.5 \pm 0.7$ & $7.4 \pm 0.7(200 \mathrm{~K})$ & 7.6 \\
\hline N2Bg & & $3.5 \pm 0.3$ & $3.7 \pm 0.4(183 \mathrm{~K})$ & \\
\hline
\end{tabular}

delay has to be applied for the ${ }^{7} \mathrm{Li}$ spin-echo decay experiments in addition to the proper soft pulse, because the relaxation times of ${ }^{7} \mathrm{Li}$ in some compounds can be extremely long even with paramagnetic doping.

${ }^{7} \mathrm{Li}$ and ${ }^{23} \mathrm{Na}$ spin-echo decays of the investigated samples are shown in Figure 4 and the $M_{2 \mathrm{E}}$ values obtained by fitting to eq $2 \mathrm{a}$ are listed in Table 4 . To test for possible ion mobility ${ }^{11,21 a}$ in N2B glass, experiments were conducted at low temperature $(\leq 200 \mathrm{~K})$ in addition to those at room temperature. The results show that the $M_{2 \mathrm{E}}$ values of $\mathrm{N} 2 \mathrm{~B}$ glass obtained at room temperature and low temperature are within the range of the systematic error $( \pm 10 \%)$ of each other. ${ }^{21}$ That shows that the $\mathrm{Na}^{+}$ions in this $\mathrm{N} 2 \mathrm{~B}$ glass are not mobile enough to affect the $M_{2 \mathrm{E}}$ values. The much smaller $M_{2 \mathrm{E}}$ value for the N2B glass compared to that of the N2B crystal suggests that the intermediate-range order of $\mathrm{N} 2 \mathrm{~B}$ glass is significantly different from that in N2B crystal. In particular, the much smaller $M_{2}$ of $\mathrm{N} 2 \mathrm{Bg}$ also means that the sodium cations are spaced farther apart and/ or are less clustered in the glass than in the crystal. In other words, the $\mathrm{Na}^{+}$distribution in N2B glass is more homogeneous than in $\mathrm{N} 2 \mathrm{~B}$ crystal. The result is consistent with a recent study on sodium borate glasses with different compositions, in which the ${ }^{23} \mathrm{Na}-{ }^{23} \mathrm{Na}$ dipole-dipole couplings exhibit toward a more homogeneous sodium distribution for those glasses with higher sodium oxide contents $(x>0.20) .{ }^{31}$ For the case of L2B, the $M_{2 \mathrm{E}}$ values of glass and crystal (Table 4) are quite similar to each other, and close to the value calculated from the crystal structure. ${ }^{14 \mathrm{a}}$ The agreement of the $M_{2 \mathrm{E}}$ values suggests the strong similarity of the intermediate-range order between the L2B glass and the L2B crystal in terms of $\mathrm{Li}^{+}$distribution.

In addition to the spin-echo decay experiments for measuring the homonuclear cation correlations, REDOR experiments were employed to investigate the heteronuclear relationships. ${ }^{11} \mathrm{~B}\left\{{ }^{6} \mathrm{Li}\right\}$ and ${ }^{11} \mathrm{~B}\left\{{ }^{23} \mathrm{Na}\right\}$ REDOR curves of L2B and N2B samples are shown in Figure 5 and the $M_{2}$ values extracted from the experimental data via eq $2 \mathrm{~b}$ are listed in Table 5. ${ }^{6} \mathrm{Li}(7.6 \%)$ instead of ${ }^{7} \mathrm{Li}(92.4 \%)$ was chosen to dephase the coherences because the $180^{\circ}$ pulse calibration of ${ }^{6} \mathrm{Li}$ is relatively simpler due to the smaller magnetic dipole moment and smaller nuclear quadrupolar moment $C_{\mathrm{q}} \cdot{ }^{29,32}$ As mentioned earlier the L2Bc and $\mathrm{N} 2 \mathrm{Bc}$ crystal samples were not only studied as investigated samples but also used as model compounds to determine the calibration factor $f$ based on calculation (eq 2b). The $f$ values were then applied to determine the $M_{2 \mathrm{E}}$ values of the corresponding glasses. The REDOR curves for $\mathrm{BO}_{4 / 2}$ and the $\mathrm{BO}_{3 / 2}$ are slightly different (not shown) while the $M_{2 \mathrm{E}}$ values obtained are almost identical, only the average $M_{2 \mathrm{E}}$ for all ${ }^{11} \mathrm{~B}$ sites were listed for comparison in this study. The results (Table 5) show again that the $M_{2 \mathrm{E}}$ values of L2B crystal and glass are similar to each other, implying that they have a very similar $\mathrm{Li}^{+}$spatial distribution around the boron nuclei. In contrast, the larger $M_{2}$ $\left({ }^{23} \mathrm{Na}-{ }^{11} \mathrm{~B}\right)$ value of the $\mathrm{N} 2 \mathrm{~B}$ glass compared to that of the crystal indicates that the average $\mathrm{Na}^{+}$to ${ }^{11} \mathrm{~B}$ distance is shorter in the glass than in the crystal.

The $M_{2 \mathrm{E}}$ values reported were obtained by fitting the initial part of the REDOR dephasing curves $\left(S_{0}-S\right) / S_{0}(<0.2)$ based 

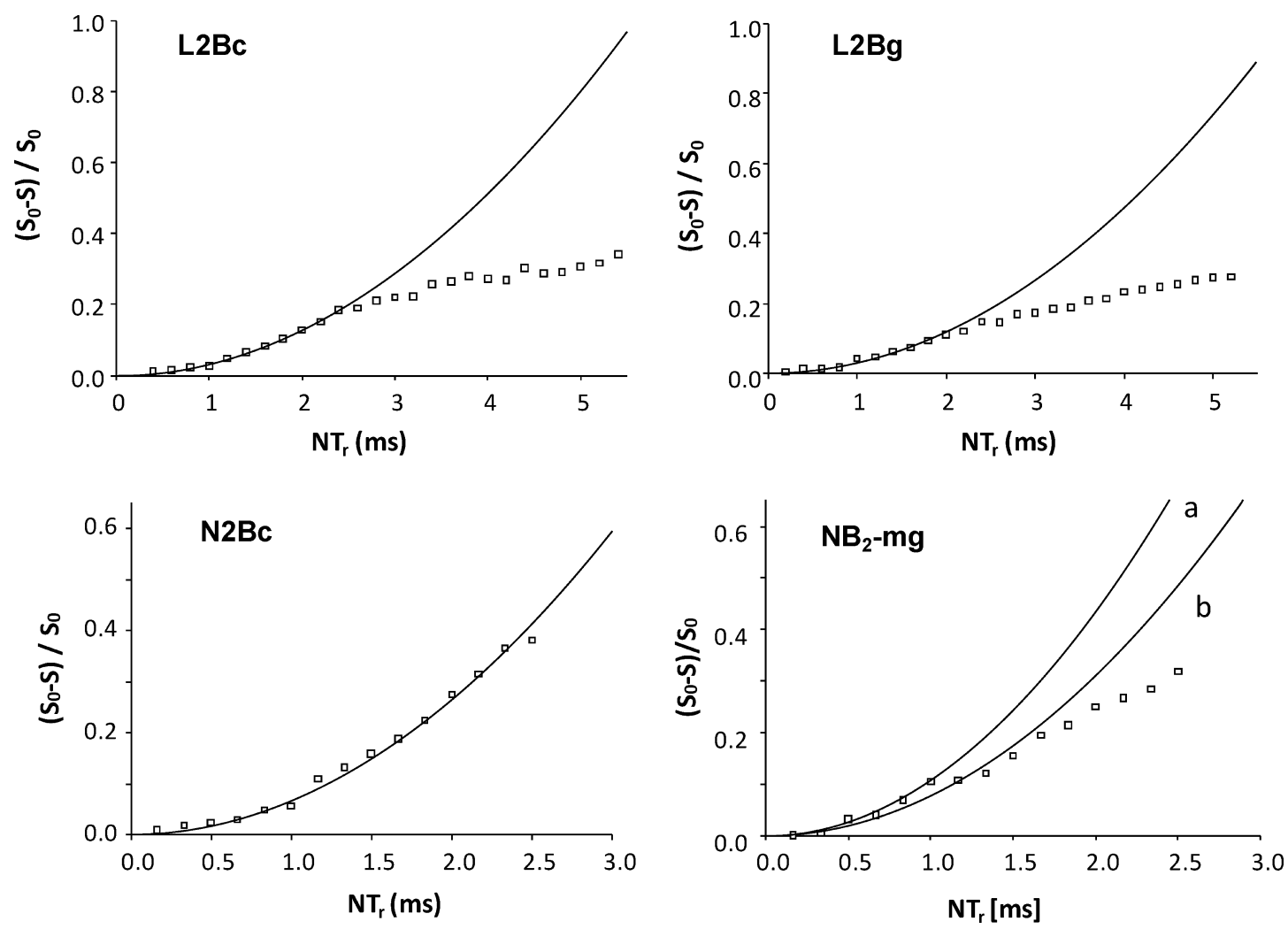

Figure 5. ${ }^{11} \mathrm{~B}\left\{{ }^{6} \mathrm{Li}\right\}$ and ${ }^{11} \mathrm{~B}\left\{{ }^{23} \mathrm{Na}\right\}$ REDOR curves of L2B and N2B crystals and glasses (dotted). The solid curves show the parabolic fit to eq $2 \mathrm{~b}$, using data up to $\Delta S / S_{0}<0.2$. For the NB2-glass case, curve (a) shows the fit for $\Delta S / S_{0}<0.1$ and curve (b) shows the fit for $\Delta S / S_{0}<0.2$.

TABLE 5: Calculated, Experimental, and Calibrated $\left(M_{2 E^{\prime}}\right)$ Second Moments and the Calibration Factor $f$ Determined from the REDOR Experiments on Crystals

\begin{tabular}{|c|c|c|c|c|c|}
\hline samples & spin-spin & $\begin{array}{c}M_{2 \mathrm{C}} \\
\left(10^{6} \mathrm{rad}^{2} / \mathrm{s}^{2}\right)\end{array}$ & $M_{2 \mathrm{E}}\left(10^{6} \mathrm{rad}^{2} / \mathrm{s}^{2}\right)$ & $f$ & $\begin{array}{c}M_{2 \mathrm{E}^{\prime}} \\
\left(10^{6} \mathrm{rad}^{2} / \mathrm{s}^{2}\right)\end{array}$ \\
\hline L2Bc & ${ }^{11} \mathrm{~B}\left\{{ }^{6} \mathrm{Li}\right\}$ & 0.42 & $0.26 \pm 0.03$ & 0.627 & 0.42 \\
\hline L2Bg & & & $0.24 \pm 0.02$ & & $0.39 \pm 0.04$ \\
\hline N2Bc & ${ }^{11} \mathrm{~B}\left\{{ }^{23} \mathrm{Na}\right\}$ & 18.7 & $2.4 \pm 0.2$ & 0.129 & 18.7 \\
\hline N2Bg & & & $3.4 \pm 0.3$ & & $26.7 \pm 3.0^{a}$ \\
\hline
\end{tabular}

${ }^{a}$ The average of the $M_{2 E^{\prime}}$ values fitted by REDOR curve a ad b in Figure 5.

on eq $2 b^{24}$ and in general are sensitive to the data range used in the fit. In this study, all REDOR curves could be well fitted by using data up to $\Delta S / S_{0}<0.2$ except for that of $\mathrm{N} 2 \mathrm{Bg}$, for which the data range had to be restricted to $\Delta S / S_{0}<0.1$ (curve (a) in the figure, while curve (b) shows the fit for $\Delta S / S_{0}<0.2$ ). The $M_{2 \mathrm{E}}$ values of N2Bg given by curves $\mathbf{a}$ and $\mathbf{b}$ are 29.6 and 23.8 $\left(\times 10^{6} \mathrm{rad}^{2} / \mathrm{s}^{2}\right)$, respectively. This variability may indicate the existence of a wide distribution of ${ }^{23} \mathrm{Na}-{ }^{11} \mathrm{~B}$ dipolar couplings in the $\mathrm{N} 2 \mathrm{Bg}$ glass, whereas the couplings in $\mathrm{N} 2 \mathrm{Bc}$ are more homogeneously distributed.

Based on above experimental results, the structural basis behind the different nucleation mechanisms can be envisaged. The L2B crystal $^{14 \mathrm{a}}$ has a three-dimensional structure consisting of a web of linked borate units, both three and four-coordinate, with the lithium ions coordinated by oxygen. There is no indication of layering or other low-dimensional ordering of compositional heterogeneities. The NMR data above show that the glass is quite similar structurally to the crystal, both in terms of short-range and intermediate range features. Therefore, it is not surprising that homogeneous nucleation occurs readily from the bulk, as little structural rearrangement would be necessary to form the crystal phase from the glass. The N2B crystal, ${ }^{14 \mathrm{~b}}$ in contrast, shows a distinctly layered structure, again consisting of linked borates but now with layers of sodium ions in roughly the crystalline $a-c$ plane. Because of volume exclusion, these layers force the sodium ions closer together than they would be in a more homogeneous distribution, leading to the enhanced $M_{2(\mathrm{Na}-\mathrm{Na})}$ in the crystal as compared to the glass.. The layering also leads to a greater diversity of local bonding environments, as judged from the MQMAS experiments, where five B3 sites are observed for the crystal, some exhibiting local structures not found in the glass. Clearly, the glass differs from the crystal at both short and intermediate length scales, necessitating large rearrangements upon crystallization. Such structural changes would be harder to initiate from the bulk and hence occur by external triggers such as walls and impurities.

\section{Conclusion}

There are two primary conclusions of this study. First, we tested and confirmed the hypothesis that there is strong correlation between the structural similarity of the glass and crystal, and the nucleation mechanism of the glass devitrification. Specifically, we found that in the sodium diborate system, the glass structure and the structure of the crystal which forms upon devitrification from the same batch are substantially different at both short and intermediate length scales, and devitrification in this system proceeds by a heterogeneous mechanism. In contrast, lithium diborate, which devitrifies by a homogeneous mechanism, exhibits essentially no structural difference between the glass and corresponding crystal. It is likely that this correlation arises from the fact that homogeneous nucleation and growth requires relatively little local rearrangement, and hence would be favored in cases with similar structures, while external triggers, as found in heterogeneous nucleation, would be required to catalyze the significant structural rearrangements necessary when glass and crystal structures differ substantially. 
The second primary conclusion is that not only significant intermediate range but also short-range structures may differ between the crystal and glass. We found in the sodium diborate case that, although as usual only coordination numbers 3 and 4 were observed for boron, the quadrupole couplings in the crystal showed a diversity not present in the glass. In silicates it appears that only structure at intermediate scales is necessary to distinguish nucleation mechanisms ${ }^{11}$ but in borates both short and intermediate range data is needed. This difference is likely due to the fact that silicate bonding at the short-range scale is particularly simple, with only tetrahedral coordination observed (under typical conditions), while in borates and frankly most other glass formers, a richer diversity of bonding occurs.

Acknowledgment. Funding from the Inter-American Materials Collaboration program of NSERC, financial support from Brazilian Research Funding Agency FAPESP (Processes 2004/ 1073-0 and 2007/08179-9), and instrumental support from IRM (Dalhousie University, Canada) are acknowledged. We thank Professor D. Massiot for the "DMfit program". We also thank Anita Lam (Chemistry Department, University of British Columbia) for the XRD measurement and phase identification.

Supporting Information Available: One table and two figures. This material is available free of charge via the Internet at http://pubs.acs.org.

\section{References and Notes}

(1) (a) Höland, W.; Beall, G. Glass-Ceramic Technology; The American Ceramic Society: Westerville, OH, 2002. (b) Qiu, J. J. Ceramic Soc. Japan 2008, 116, 593. (c) Wu, L.; Chen, F.; Zhang, X. Taoci (Xianyang, China) 2008, 12, 15. (d) Höland, W.; Rheinberger, V. Global Roadmap Ceram. Glass Technol. 2007, 225. (e) Beall, G. H. Annu. Rev. Mater. Sci. 1992, 2 553. (f) ManFredini, T., Pellacani, G. C., Rincon, J. M., Eds.; Glass-Ceramic Materials. Fundamentals and Applications; Mucchi Editore: Modena, Italy, 1997.

(2) Souza, L. A.; Leite, M. L. G.; Zanotto, E. D.; Prado, M. O. J. NonCryst. Solids 2005, 351, 3579.

(3) (a) Schneider, J.; Mastelaro, V. R.; Panepucci, H.; Zanotto, E. D. J. Non-Cryst. Solids 2000, 273, 8. (b) Mastelaro, V. R.; Zanotto, E. D. Lequeux, N.; Cortes, R. J. Non-Cryst. Solids 2000, 262, 191. (c) Deubener, J. J. Non-Cryst. Solids 2003, 351, 1500.

(4) Eckert, H.; Elbers, S.; Epping, J. D.; Janssen, M.; Kalwei, M.; Strojek, W.; Voigt, U. Top. Curr. Chem. 2004, 246, 195.

(5) (a) Elliott, S. R. Nature 1981, 294, 692. (b) Zachariasen, W. H. J. Am. Chem. Soc. 1932, 54, 3841. (c) Selvaray, U.; Rao, K. J.; Rao, C. N. R.; Klinowski, J.; Thomas, J. M. Chem. Phys. Lett. 1985, 114, 24 (d) Uhlig, H.; Hoffmann, M. J.; Lamparter, H.; Aldinger, F.; Bellissent, R.; Steeb, S. J. Am. Ceram. Soc. 1996, 79, 2839. (e) Zhao, J.; Gaskell, P. H.; Cluckie, M. M.; Soper, A. K. J. Non-Cryst. Solids 1998, 232-234, 721. (f) Huang, C.; Cormack, A. N. J. Chem. Phys. 1990, 93, 8180. (g) Uhlig, H.; Hoffmann, M. J.; Lamparter, H.; Aldinger, F.; Bellissent, R.; Steeb, S. J. Am. Ceram. Soc. 1996, 79, 2833. (h) Warren, B. E.; Loring, A. D. J. Am. Ceram. Soc. 1935, 18, 269.

(6) (a) Maekawa, H.; Maekawa, T.; Kawamura, K.; Yokokawa, T. J. Non-Cryst. Solids 1991, 127, 53. (b) Janes, N.; Oldfield, E. J. Am. Chem. Soc. 1985, 107, 6769. (c) Emerson, J. F.; Stallworth, P. E.; Bray, P. J. J. Non-Cryst. Solids 1989, 113, 253. (d) Stebbins, J. F. Nature 1987, 330 , 465.

(7) Gaskell, P. H. J. Non-Cryst. Solids 2005, 351, 1003.

(8) (a) Mackenzie, K. J. D.; Smith, M. E. Multinuclear Solid-State NMR of Inorganic Materials; Pergamon: Amsterdam, 2002; and references therein. (b) Zwanziger, J. W. Inter. Rev. Phys. Chem. 1998, 17, 65. (c) Gullion, T. Vega, A. J. Prog. Nucl. Magn. Reson. Spectrosc. 2005, 47, 123. (d) Montagne, L.; Delevoye, L. Spectra Analyse 2005, 34, 26. (e) Ratai, E. M.; Janssen, M.; Epping, J. D.; Chan, J. C. C.; Eckert, H. Phys. Chem. Glasses 2003, 44, 45. (f) Ren, H. L.; Yue, Y.; Ye, C. H. Wuji Hиахие Xиebao 1999, $15,151$.
(9) (a) Zwanziger, J. W.; Youngman, R. E.; Braun, M. Borate Glasses, Crystals \& Melts. In Proceedings of the International Conference on Borate Glasses, Crystals \& Melts, 2nd ed.; Abingdon, 1997; p 21. (b) Schneider, J.; Mastelaro, V. R.; Zanotto, E. D.; Shakhmatkin, B. A.; Vedishcheva, N. M.; Wright, Adrian, C.; Panepucci, H. J. Non-Cryst. Solids 2003, 325, 164. (c) Stebbins, J. F.; Zhao, P.; Kroeker, S. Solid State Nucl. Magn. Reson. 2000, 16, 9. (e) Hansen, M. R.; Vosegaard, T.; Jakobsen, H. J.; Skibsted, J. J. Phys. Chem. A 2004, 108, 586. (f) Aguiar, P. M.; Kroeker, S. J. NonCryst. Solids 2007, 353, 1834.

(10) van Vleck, J. H. Phys. Rev. 1948, 33, 1168.

(11) Longstaffe, J. G.; Werner-Zwanziger, U.; Schneider, J. F.; Nascimento, M. L. F.; Zanotto, E. D.; Zwanziger, J. W. J. Phys. Chem. C 2008, 112,6151 .

(12) (a) MacDonald, R. L.; Lawandy, N. M. Phys. Rev. B 1993, 47, 1961. (b) Liu, H.; Liu, Q.; Wang, M.; Zhao, X. J. Phys. Chem. Solids 2007, 68, 963. (c) Simon, J. M.; Smith, R. A. Borates and their use in the glass industry. In Proceedings of International Congress on Glass, 18th ed.; San Francisco, CA, 1998; p 71. (d) Yiannopulos, Y. D.; Chryssikos, G. D.; Kamitsos, E. J. Phys. Chem. Glasses 2001, 42, 164. (e) Chryssikos, G. D.; Bitsis, M. S.; Kapoutsis, J. A.; Kamitsos, E. I. J. Non-Cryst. Solids 1997, 217, 278.

(13) (a) Smith, G. L.; Weinberg, M. C. Phys. Chem. Glasses 1991, 32, 37. (b) Souza, L. A. Nucleation and growth in LB2 glass; Ph.D. Thesis, Federal University of São Carlos (in Portuguese), 2006. (c) Nagel, S.; Bergeron, C. G. J. Am. Ceram. Soc. 1974, 57, 129. (d) Li, H.; Liang, J. J. Am. Ceram. Soc. 1995, 78, 470, and references therein.

(14) (a) Krogh-Moe, J. Acta Cryst. B 1968, 24, 179. (b) Krogh-Moe, J. Acta Cryst. B 1974, 30, 578.

(15) (a) Haase, J.; Oldfield, E. J. Magn. Reson. A 1993, 101, 30. (b) Hasse, J.; Oldfield, E. J. Magn. Reson. A 1993, 104, 1.

(16) Dumazy, Y.; Amoureux, J. P.; Fernandez, C. Mol. Phys. 1997, 90 , 959.

(17) Abragam, A. Principles of Nuclear Magnetism; Oxford University Press: Oxford, U.K., 1961.

(18) Mortuza, M. G.; Dupree, R.; Holland, D. J. Mater. Sci. 2000, 35 , 2829

(19) Reynhardt, E. C. Can. J. Phys. 1989, 67, 592.

(20) (a) Ratai, E.; Janssen, M.; Eckert, H. Solid State Ionics 1998, 105, 25. (b) Gee, B.; Eckert, H. Solid State Nucl. Magn. Reson. 1995, 5, 113.

(21) Zwanziger, J. W.; McLaughlin, J. C.; Tagg, S. L. Phys. Rev. B 1997, 56, 5243 .

(22) (a) Gullion, T.; Schaefer, J. J. Magn. Reson. 1989, 81, 196. (b) Pan, Y.; Gullion, T.; Schaefer, J. J. Magn. Reson. 1990, 90, 330.

(23) (a) van Wüllen, L.; Eckert, H.; Schwering, G. Chem. Mater. 2000, 12, 1840. (b) Strojek, W.; Kalwei, M.; Eckert, H. J. Phys. Chem. B 2004, 108, 7061. (c) Strojek, W.; Eckert, H. Phys. Chem. Chem. Phys. 2006, 8, 2276. (d) Zhang, L.; Eckert, H. J. Mater. Chem. 2005, 15, 1640. (e) ZeyerDüsterer, M.; Montagne, L.; Palavit, G.; Jäger, C. Solid State Nucl. Magn. Reson. 2005, 27, 50. (f) Janssen, M.; Eckert, H. Solid State Ionics 2000, 136-137, 1007. (g) van Wüllen, L.; Gee, B.; Züchner, L.; Bertmer, M.; Eckert, H. Ber. Bunsen-Ges. Phys. Chem. 1996, 100, 1539. (h) Gee, B.; Janssen, M.; Eckert, H. J. Non-Cryst. Solids 1997, 215, 41. (i) Voigt, U.; Lammert, H.; Eckert, H.; Heuer, A. Phys. Rev. B 2005, 72, 064207.

(24) Bertmer, M.; Zuchner, L.; Chan, J. C. C.; Eckert, H. J. Phys. Chem. B 2000, 104, 6541 .

(25) Smith, M. E.; van Eck, E. R. H. Prog. Nucl. Magn. Resonan. Spectrosc. 1999, 34, 159.

(26) Brown, S. P.; Wimperis, S. J. Magn. Reson. 1997, 128, 42.

(27) Massiot, D.; Fayon, F.; Capron, M.; King, I.; Le Calvé, S.; Alonso, B.; Durand, J.-O.; Bujoli, B.; Gan, Z.; Hoatson, G. Magn. Reson. Chem. 2002, 40, 70 .

(28) Fokin, V. M.; Zanotto, E. D.; Yuritsyn, N. S.; Schmelzer, J. W. P. J. Non-Cryst. Solids 2006, 352, 2681.

(29) Xia, Y.; Machida, N.; Wu, X.; Lakeman, C.; van Wullen, L.; Lange, F.; Levi, C.; Eckert, H. J. Phys. Chem. B 1997, 101, 9180.

(30) Zogal, O. J.; Beuneu, F.; Vajda, P.; Florian, P.; Massiot, D. Phys. Rev. B 2002, 66, 064101 .

(31) Epping, J. D.; Strojek, W.; Eckert, H. Phys. Chem. Chem. Phys. 2005, 7, 2384.

(32) (a) Hasiuk, T.; Jeffrey, K. R. Solid State Nucl. Magn. Resonan. 2008, 34, 228. (b) Eckert, H.; Zhang, Zh.; Kennedy, J. H. Chem. Mater. 1990, 2, 279 .

JP907259E 